\title{
Gastrointestinal implications in pigs of wheat and oat fractions
}

\author{
2. Microbial activity in the gastrointestinal tract \\ BY K. E. BACH KNUDSEN, B. BORG JENSEN, J. O. ANDERSEN \\ AND INGE HANSEN \\ Department of Animal Physiology and Biochemistry, National Institute of Animal Science, Foulum, \\ P.O. Box 39, DK-8830 Tjele, Denmark
}

(Received 16 November 1989 - Accepted 7 August 1990)

\begin{abstract}
The present work was undertaken to study the microbial activity in various segments of the gastrointestinal (GI) tract of pigs as influenced by the source and level of wheat and oat dietary fibre (DF). Eight experimental diets were prepared from wheat and oat fractions and studied in a series of two experiments using wheat flour as the DF-depleted control. The diets in Expt 1 were based on wheat flour and three iso-DF enriched diets comprising fractions rich in wheat aleurone, pericarp/testa or bran. In Expt 2, oat bran was added to wheat flour to achieve the same DF intake level as in Expt 1. This series included further diets based on rolled oats and rolled oats plus oat bran. The eight diets were given to thirty-two ileal-cannulated pigs, with sixteen pigs in each experiment. After a total period of $34 \mathrm{~d}$ (Expt 1) and $42 \mathrm{~d}$ (Expt 2), the pigs were slaughtered $4 \mathrm{~h}$ post-feeding and samples taken for adenine nucleotides (adenosine 5'-triphosphate (ATP); adenylate energy charge (AEC)), organic acids (lactic acid (LA); short chain fatty acids (SCFA)) and $\mathrm{pH}$ at twelve sites of the GI tract. The microhial activity as measured by the ATP concentration was low in the stomach and the cranial two-thirds of the small intestine, but tended to increase in the distal third. In the caecum a sharp rise in microbial activity was observed; the highest level was found for the diet providing most fermentable substrates. In all the diets but the rolled oats + oat bran diets, microbial activity showed a descending pattern as the digesta moved through the colon. In the large intestine source and level of residues had a marked influence on microbial activity. LA was the chief organic acid in the stomach and small intestine $(10-40 \mathrm{mmol} / \mathrm{l})$ while $L A$ relative to SCFA was a minor component in the caecum and colon $(10-20 \mathrm{mmol} / \mathrm{l})$. The contribution of SCFA to total organic acids was reciprocal to LA, i.e. low in the stomach and small intestine $(<20 \mathrm{mmol} / \mathrm{l})$ and high in the caecum and colon. In the large intestine the concentration of SCFA decreased from $100-140 \mathrm{mmol} / \mathrm{l}$ in the caecum and proximal colon to $40-80 \mathrm{mmol} / \mathrm{l}$ in the distal colon. The acetic: propionic acid ratio increased from the caecum to the distal colon. With the diets based on oat alone (rolled oats; rolled oats + oat bran) the increase was less significant. DF addition and oats in particular increased the butyric acid molar ratio, from 0.06-0.08 for the wheat flour diet to 0.10-0.12 for the diet based on rolled oats + oat bran. For the same two diets the proportion of isobutyric and isovaleric acids increased more rapidly with the wheat-flour diet compared with the rolled oats + oat bran diet.
\end{abstract}

Microbial activity: Adenylate energy charge: Dietary fibre: Pig

Microbial fermentation occurs to a varying degree in the gastrointestinal (GI) tract of most mammals including pigs and man (Argenzio \& Southworth, 1975; Clemens et al. 1975; Cummings, 1982; Cummings \& Englyst, 1987). Transit of fluid and particulate markers through the stomach and small intestine of pigs is generally rapid with little or no accumulation at any point (Clemens et al. 1975). These conditions are unfavourable for the establishment of prolific microbial growth and most studies show a relatively low microbial activity in these GI segments (Fuller et al. 1960; Savage, 1977). In contrast, in the large intestine, materials may be retained for prolonged periods of time (20-38 h) (Hill, 1969; Keys \& DeBarthe, 1974), which allows prolific microbial growth (Decuypere \& Van der 
Heyde, 1972). Concurrently extensive microbial degradation of endogenous and exogenous materials is seen in these GI segments (Mason \& Just, 1976; Graham et al. 1986; Bach Knudsen \& Hansen, 1991). The principal energy substrate for microbial fermentation is carbohydrate, with the end-products: lactic acid (LA), short-chain fatty acids (SCFA; acetic, propionic and butyric acids) and various gases (hydrogen, carbon dioxide, methane). LA is the chief organic acid present in digesta from the stomach and small intestine (Argenzio \& Southworth, 1974; Clemens et al. 1975), while SCFA predominate in the large intestine (Argenzio \& Southworth, 1974; Clemens et al., 1975).

The renewed interest in the role of dietary fibre (DF) in health and disease has focused attention to the GI tract and metabolic implications of various DF sources (Cummings, 1982; Cummings \& Branch, 1982). SCFA are the main anions in the large intestine of pigs (Argenzio \& Whipp, 1979) and of man (Cummings et al. 1979, 1987). The SCFA produced are rapidly absorbed from the gut lumen of simple-stomached animals (McNeil et al. 1978; Argenzio \& Whipp, 1979), stimulate sodium and water absorption (Argenzio \& Whipp, 1979) and play an important role in the energy supply (Bach Knudsen \& Hansen, 1991). The SCFA absorbed might have different effects in the body. Butyrate is believed to have important implications for the metabolism, structure and function of epithelial cells lining the large intestine (Ryan et al. 1979; Cummings \& Branch, 1982; Sakata \& Yajima, 1984) where it is the preferred fuel over glucose (Roediger, 1980), while propionate may modify hepatic metabolism (Chen et al. 1984).

The adenosine nucleotides are energy couplers between catabolic and anabolic processes in all living cells, and measurements of ATP (adenosine $5^{\prime}$-triphosphate), ADP (adenosine $5^{\prime}$-diphosphate) and AMP (adenosine 5'-monophosphate) have been used as indicators of the amount of energy available for metabolic processes (Chapman et al. 1971). Although rumen studies by Forsberg \& Lam (1977) have caused doubt about the use of the ATP concentration as an indicator of microbial activity in rumen fluid, studies at this Institute with rats and pigs (Bach Knudsen et al. 1982a,b; 1984; Jensen, 1988) suggest that ATP might be a useful indicator for microbial activity in the GI tract of simple-stomached animals. Studies by Swedes et al. (1975) have shown that the rate of protein synthesis and the potential for cellular biosynthesis are more closely correlated with changes in adenylate energy charge (AEC) than with fluctuations in absolute concentrations of intracellular adenine nucleotides. AEC is defined as (ATP + 0.5 ADP)/(ATP + ADP + AMP) and was originally proposed to describe the regulation of enzyme reactions which synthesize or utilize ATP (Atkinson \& Walton, 1967).

In the preceding paper (Bach Knudsen \& Hansen, 1991) we reported the effect of wheat and oat DF on digestion and bulking properties in pigs. The aim of the present part of the investigation was to study the effect of the various DF sources on microbial activity and products formed in various segments of the GI tract of pigs.

\section{EXPERIMENTA L}

\section{Experimental Diets}

The experimental diets comprised the eight diets characterized with regard to dietary composition and bulking properties in the preceding paper (Bach Knudsen \& Hansen, 1991). The diets were based on refined wheat flour (WF) (low DF, control), wheat flour + aleurone (WFA), wheat flour + pericarp/testa (WFPT), wheat flour + wheat bran (WFWB), wheat flour + oat bran (WFOB), rolled oats (RO) and rolled oats + oat bran ( $R O O O B)$. The diets were tested in a series of two experiments using diet WF as the low DF control (diets WF1 and WF2, Table 1). The low DF control provided on the day of 
slaughtering $62 \mathrm{~g} \mathrm{DF} / \mathrm{d}$; diet WFA, WFPT, WFWB and WFOB 95-116 g DF/d; diet RO $168 \mathrm{~g} \mathrm{DF} / \mathrm{d}$; and diet ROOB $194 \mathrm{~g} \mathrm{DF} / \mathrm{d}$.

\section{Animals and feeding}

A total of thirty-two ileal-cannulated pigs, sixteen pigs (four herds of four littermates) in each series of experiments, were used. The sixteen pigs were divided into four groups (one group/diet) with one littermate from each herd in each group. After finishing the balance experiment, the pigs were fed for an additional $6 \mathrm{~d}$ in Expt 1 or $14 \mathrm{~d}$ in Expt 2. On day 34 (Expt 1) and day 42 (Expt 2) the pigs were given the morning ration and killed $4 \mathrm{~h}$ postfeeding. Immediately after slaughtering, the GI tract was removed and separated by ligatures into twelve sections (Clemens et al. 1975). These comprised the cranial and caudal halves of the stomach $\left(\mathrm{S}_{1}, \mathrm{~S}_{2}\right)$, three equal segments of the small intestine $\left(\mathrm{SI}_{1}, \mathrm{SI}_{2}, \mathrm{SI}_{3}\right)$, the caecum $(\mathrm{Ce})$ and six segments of the colon $\left(\mathrm{C}_{1}, \mathrm{C}_{2}, \mathrm{C}_{3}, \mathrm{C}_{4}, \mathrm{C}_{5}, \mathrm{C}_{6}\right)$. The latter consisted of the proximal, two ascending, two descending and the distal segments. With the exception of the stomach there was hardly any exchange between the contents of the different segments of the gut before ligaturing. The total contents of each GI segment were carefully collected for determination of dry matter, $\mathrm{pH}$, adenine nucleotides, LA and SCFA. The samples for determination of adenine nucleotides were collected in cold perchloric acid/ethylenediamine tetra-acetic acid (PCA/EDTA), mixed and stored at $-80^{\circ}$, while the other samples were frozen immediately and stored at $-20^{\circ}$ until analysed. For samples drawn for ATP determinations it was particularly important to avoid contamination with blood and mucosa.

\section{Analytical methods}

Analyses of SCFA and LA were performed on undried samples whereas the other analyses were carried out on freeze-dried material. Dry matter contents of GI samples were determined by freeze drying. The $\mathrm{pH}$ in digesta was measured using a glass electrode (Type G2040/C; Radiometer A/S, Copenhagen, Denmark) using a mercury-mercury chloride electrode as reference (Type K9040; Radiometer A/S). Total LA (D and L) was determined by means of specific enzymes in a coupled enzymic reaction with nicotinamide-adenine dinucleotide $\left(\mathrm{NAD}^{+}\right)$and SCFA by gas-liquid chromatography as described by Bach Knudsen \& Hansen (1991).

The concentration of adenine nucleotides in digesta contents was estimated by the luciferin-luciferase (EC 1.13.12.7) method (McElroy, 1947; Wolstrup \& Jensen, 1976). This assay is based on the quantitative measurement of light produced by an enzyme reaction between ATP and luciferin catalysed by firefly luciferase. The light intensity is directly proportional to the concentration of ATP and is calculated as the light intensity relative to that of an ATP standard. The adenine nucleotides in digesta $(1.5 \mathrm{~g})$ were extracted with PCA/EDTA $\left(2 \mathrm{M}-\mathrm{HClO}_{4} / 10 \mathrm{mM}\right.$-EDTA; $\left.3 \mathrm{ml} ; 0^{\circ}\right)$ and carefully mixed using a whirlmixer. After centrifugation $\left(5500 \mathrm{~g}, 30 \mathrm{~min}, 0^{\circ}\right), 2.0 \mathrm{ml}$ of the supernatant fraction was neutralized with potassium hydroxide $(0.5 \mathrm{M})$ to $\mathrm{pH} 7 \cdot 0-7.5$. In order to obtain a highly buffered sample, $0.4 \mathrm{ml}$ Tris-buffer $(0.2 \mathrm{M}, \mathrm{pH} 7 \cdot 4)$ was added before neutralization. After recentrifugation $\left(5500 \mathrm{~g}, 10 \mathrm{~min}, 4^{\circ}\right)$ the amount of adenine nucleotides was measured. ATP was determined by use of an ATP monitoring kit (LKB-Wallace AB, Sweden), with a luminometer (1251 Luminometer; LKB-Wallace AB) (Thore, 1979). ATP in the samples was determined directly, while ADP and AMP were measured after conversion to ATP. ADP was converted to ATP by phosphoenolpyruvate (PEP) (Boehringer Mannheim GmbH, Mannheim, Germany) and pyruvate kinase (EC 2.7.1.40; PK; Boehringer Mannheim $\mathrm{GmbH}$ ), and AMP by PEP, PK myokinase (EC 2.7.4.3; 
Boehringer Mannheim $\mathrm{GmbH}$ ). The adenine nucleotides in the digesta samples are expressed as $\mathrm{AEC}$ calculated as:

$$
\mathrm{AEC}=\frac{(\mathrm{ATP}+1 / 2 \mathrm{ADP})}{(\mathrm{ATP}+\mathrm{ADP}+\mathrm{AMP})}
$$

\section{Statistical analysis}

The analytical data from the various sampling points of the GI tract were tested separately for each of the two experiments for homogeneity according to Barlett's test (Snedecor \& Cochran, 1973). The homogeneity test showed that for AEC, SCFA molar ratio and $\mathrm{pH}$ the values for all GI segments could be pooled, whereas for ATP, SCFA and LA the data set was homogeneous only within the stomach and small intestine $\left(\left(\mathrm{S}_{1}, \mathrm{~S}_{2}, \mathrm{SI}_{1}, \mathrm{SI}_{2}, \mathrm{SI}_{3}\right)\right.$ or within the large intestine $\left(\mathrm{Ce}, \mathrm{C}_{1}, \mathrm{C}_{2}, \mathrm{C}_{3}, \mathrm{C}_{4}, \mathrm{C}_{5}, \mathrm{C}_{6}\right)$ respectively. After doing the homogeneity test, the analytical values within the previous stated groups were subjected to statistical analysis with a two-way analysis of variance (ANOVA) model (Snedecor \& Cochran, 1973):

$$
X_{i j k}=\mu+\alpha_{i}+\beta_{j}+(\alpha \beta)_{i j}+\epsilon_{i j k}
$$

where $X_{i j}$ is the dependent variable (i.e. ATP values etc.), $\mu$ is the overall mean, $\alpha_{i}$ is the effect of diet, $\beta_{j}$ is the effect of GI segment, and $\epsilon_{i j k}$ is a normally distributed random variable.

\section{RESULTS}

\section{Digestion of nutrients in the large intestine}

The total amount of energy $(\mathrm{kJ} / \mathrm{d})$ absorbed from the large intestine varied from $1606 \mathrm{~kJ}$ for diet WF1 to $4440 \mathrm{~kJ}$ for diet ROOB (Table 2). The bulk of the absorbed energy was derived from digestion of carbohydrates of which NSP (non-starch polysaccharides) was the most important $(40 \cdot 1-106 \cdot 3 \mathrm{~g} / \mathrm{d})$. Starch in Expt 1 contributed only a small amount $(3 \cdot 5-7 \cdot 7 \mathrm{~g} / \mathrm{d})$, while the amount in Expt 2 was much higher $(17 \cdot 5-42 \cdot 7 \mathrm{~g} / \mathrm{d})$. Of the other dietary constituents, low-molecular-weight (LMW) sugars and fructans amounted to $2 \cdot 0-21.9 \mathrm{~g} / \mathrm{d}$, fat to $-3 \cdot 7-9.5 \mathrm{~g} / \mathrm{d}$ and nitrogen to $1 \cdot 27-5 \cdot 31 \mathrm{~g} / \mathrm{d}$.

\section{Adenine nucleotides}

The ATP concentration $(\mu \mathrm{g} / \mathrm{g}$ digesta) was low $(1-3 \mu \mathrm{g} / \mathrm{g})$ in the stomach and proximal small intestine (Fig. 1). In Expt 1 there was a slight increase in ATP concentration to $5-7 \mu \mathrm{g} / \mathrm{g}$ and further to $7-13 \mu \mathrm{g} / \mathrm{g}$ in the mid- and distal small intestine, while in Expt 2 ATP concentration in all segments of the upper GI tract was below $5 \mu \mathrm{g} / \mathrm{g}$. The ATP concentration in both experiments increased sharply in the caecum to a level of $26-35 \mu \mathrm{g} / \mathrm{g}$ in Expt 1 and to $30-45 \mu \mathrm{g} / \mathrm{g}$ in Expt 2 ; the highest level found was for diet ROOB $(P<0.05)$. More marked differences for the eight diets were found in the colon, where the general order of ATP content was: diets WF $1<\mathrm{WFPT}<\mathrm{WF} 2<\mathrm{WFA}<\mathrm{WFWB}<$ WFOB $<\mathrm{RO}<\mathrm{ROOB}$. When the amount of energy was limiting (diet WF1) there was a rapid decrease in ATP concentration; the concentration in the distal colon was in the same order as in the stomach and proximal small intestine $(2-3 \mu \mathrm{g} / \mathrm{g})$. Addition of DF to achieve iso-DF levels (diets WFA, WFPT, WFWB, WFOB) stimulated microbial activity, with wheat and oat bran and wheat aleurone having a significantly greater effect than pericarp/testa. With the three former DF sources, ATP peaked $(33-37 \mu \mathrm{g} / \mathrm{g})$ in the 
Table 1. Composition of experimental diets ( $\mathrm{g} / \mathrm{kg}$ dry matter)

\begin{tabular}{|c|c|c|c|c|c|c|c|c|}
\hline \multirow[b]{2}{*}{ Diet $^{*} \ldots$} & \multicolumn{4}{|c|}{ Expt 1} & \multicolumn{4}{|c|}{ Expt 2} \\
\hline & WF1 & WFA & WFPT & WFWB & WF2 & WFOB & RO & ROOB \\
\hline Wheat fiour & 794 & 675 & 744 & 740 & 794 & 705 & - & - \\
\hline Wheat aleurone & - & 174 & - & - & - & - & - & - \\
\hline Wheat pericarp/testa & - & - & 72 & - & - & - & - & - \\
\hline Wheat bran & - & - & - & 82 & - & - & -. & - \\
\hline Rolled oats & - & - & - & - & - & - & 892 & 794 \\
\hline Oat bran & - & - & - & - & - & 154 & - & 151 \\
\hline Casein & 122 & 79 & 105 & 100 & 122 & 66 & 70 & 21 \\
\hline Soya-bean oil & 46 & 39 & 43 & 42 & 46 & 41 & - & - \\
\hline Vitamin/mineral mixture & 34 & 29 & 32 & 32 & 34 & 30 & 34 & 30 \\
\hline Chronic oxide (marker) & 4 & 4 & 4 & 4 & 4 & 4 & 4 & 4 \\
\hline
\end{tabular}

WF1, WF2, wheat flour; WFA, wheat flour + aleurone; WFPT, wheat flour + pericarp/testa; WFWB, wheat flour + wheat bran; WFOB, wheat flour + oat bran; RO, rolled oats; ROOB, rolled oats + oat bran.

* For chemical composition see Bach Knudsen \& Hansen (1991).

Table 2. Calculated $\dagger$ digestion of nutrients $(\mathrm{g} / \mathrm{d})$ and absorption of energy $(k J / d)$ in the large intestine of pigs fed on wheat- and oat-based diets

\begin{tabular}{|c|c|c|c|c|c|c|c|c|}
\hline \multirow[b]{2}{*}{ Diet $^{*} \ldots$} & \multicolumn{4}{|c|}{ Expt 1} & \multicolumn{4}{|c|}{ Expt 2} \\
\hline & WFI & WFA & WFPT & WFWB & WF2 & WFOB & RO & ROOB \\
\hline \multicolumn{9}{|l|}{ Energy } \\
\hline Total $(\mathrm{kJ})$ & 1606 & 1858 & 1286 & 2302 & 2405 & 2328 & 4214 & 4440 \\
\hline $\mathrm{CHO}(\mathrm{kJ})$ & 1134 & 1427 & 1152 & 1760 & 1607 & 1708 & 2781 & 3059 \\
\hline \multicolumn{9}{|l|}{ Nutrients } \\
\hline Nitrogen (g) & $2 \cdot 19$ & 1.90 & 1.27 & $2 \cdot 50$ & $3 \cdot 35$ & 2.93 & $5 \cdot 31$ & 4.63 \\
\hline Fat $(\mathrm{g})$ & 0.6 & $-0 \cdot 2$ & $-3 \cdot 7$ & 0.8 & $3 \cdot 3$ & 0.5 & $9 \cdot 5$ & 8.8 \\
\hline LMW-sugars + fructans $(\mathrm{g})$ & 8.0 & $13 \cdot 2$ & 116 & $10 \cdot 1$ & 21.9 & 16.8 & $2 \cdot 7$ & $2 \cdot 0$ \\
\hline Starch $(\mathrm{g})$ & 3.5 & 4.9 & $3 \cdot 5$ & $7 \cdot 7$ & $26 \cdot 7$ & 17.5 & 40.5 & $42 \cdot 7$ \\
\hline $\operatorname{NSP}(\mathrm{g})$ & $40 \cdot 1$ & 58.9 & $46 \cdot 3$ & $60 \cdot 0$ & $44 \cdot 6$ & $55 \cdot 2$ & 101.5 & $106 \cdot 3$ \\
\hline
\end{tabular}

LMW-sugars, low-molecular weight sugars (sum of fructose and sucrose); CHO, carbohydrates; NSP, nonstarch polysaccharides; WF1, WF2, wheat flour; WFA, wheat flour+aleurone; WFPT, wheat flour + pericarp/testa; WFWB, wheat flour + wheat bran; WFOB, wheat flour + oat bran; RO, rolled oats; ROOB, rolled oats + oat bran.

* For details of diets, see Table 1.

$\dagger$ Values based on feed intake on the day of slaughtering and digestibility coefficient obtained in the balance period (Bach Knudsen \& Hansen, 1991).

proximal colon, while addition of pericarp/testa only resulted in an ATP concentration which was slightly higher than that for diet WF1. The highest ATP concentration $(32-46 \mu \mathrm{g} / \mathrm{g})$ in all segments of the colon was achieved with diet ROOB, where the microbial activity was maintained at a constantly high level in contrast to the other diets where ATP concentration decreased. The correlation between the average ATP concentration of the large intestine and the amount of digested carbohydrates was highly significant $(r 0.77, P<0.001$; Fig. 2).

AEC in the caecum was 0.60-0.85 in Expt 1 and 0.55-0.75 in Expt 2. Appreciably lower values were found in the three investigated segments of the colon $\left(\mathrm{C}_{1}, \mathrm{C}_{4}, \mathrm{C}_{6}\right)$ (Fig. 3). This was particularly the case when giving the control diet (diets WF1 and WF2), providing 


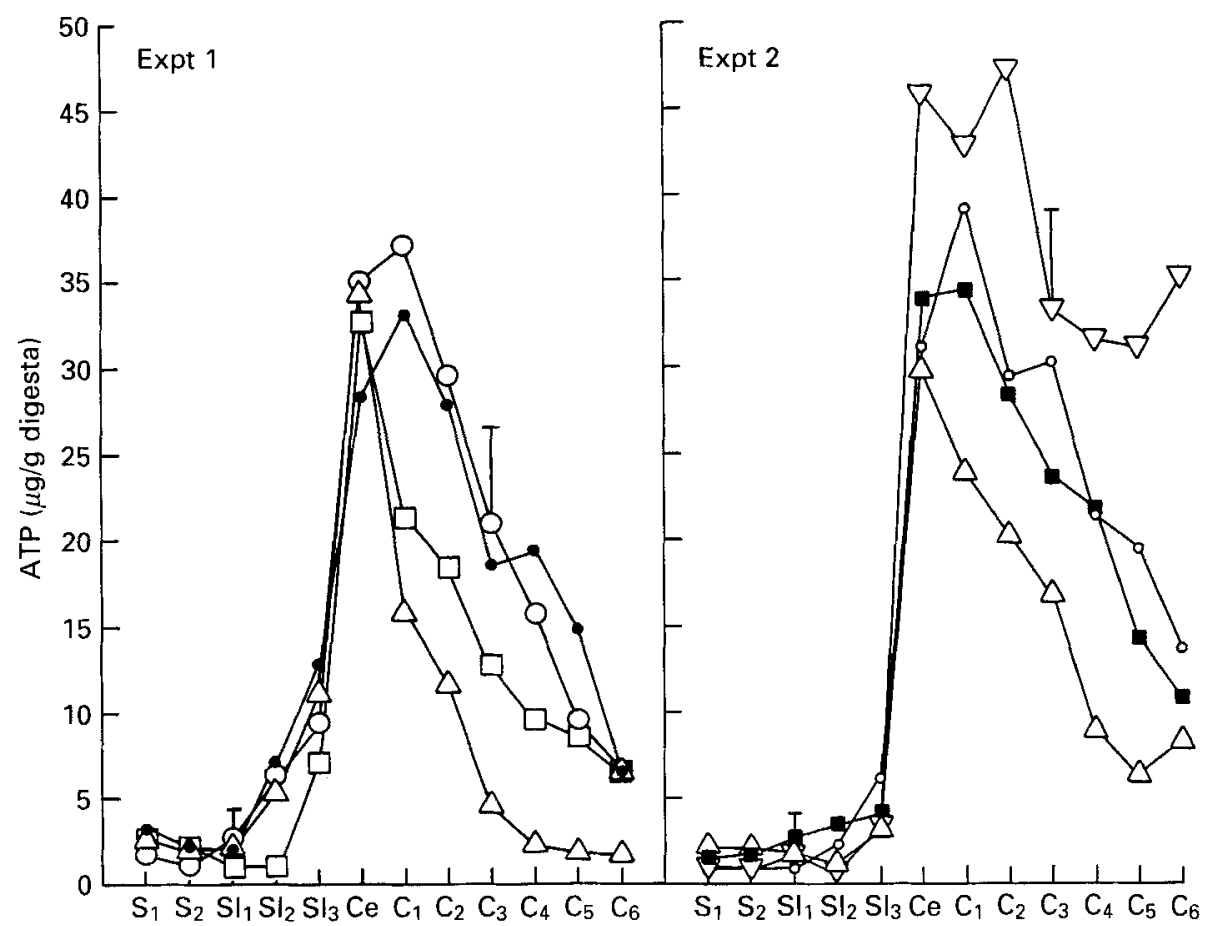

Fig. 1. Expts 1 and 2. ATP concentration of the gastrointestinal contents of pigs. The four diets in Expt 1 were: $\triangle-\triangle$ wheat flour, $0-0$ wheat flour + aleurone, $\square-\square$ wheat flour + pericarp/testa, -0 wheat flour + wheat bran and in Expt 2: $\triangle-\triangle$ wheat flour, - wheat flour + oat bran, $\mathrm{O}-\mathrm{O}$ rolled oats and $\nabla-\nabla$ rolled oats + oat bran. The various segments of the gastrointestinal tract were: $S_{1}$ and $S_{2}$, cranial and caudal halves of stomach; $\mathbf{S I}_{1}, \mathbf{S I}_{2}$ and $\mathrm{SI}_{3}$, three equal segments of small intestine; $\mathrm{Ce}$, caecum; $\mathbf{C}_{1}$, proximal colon; $\mathrm{C}_{2}$ and $\mathrm{C}_{3}$, ascending colon $; \mathrm{C}_{4}$ and $\mathrm{C}_{5}$, descending colon; and $\mathrm{C}_{6}$, distal colon. Values are means with their standard errors represented by vertical bars. For details of diets see Table 1.

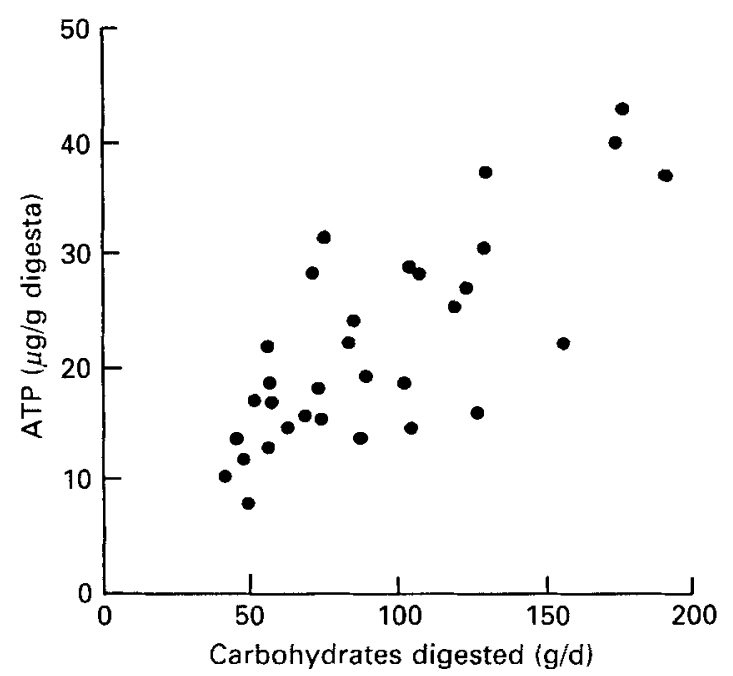

Fig. 2. Correlation between the average ATP concentration in the large intestine and the amount of carbohydrate digested. 


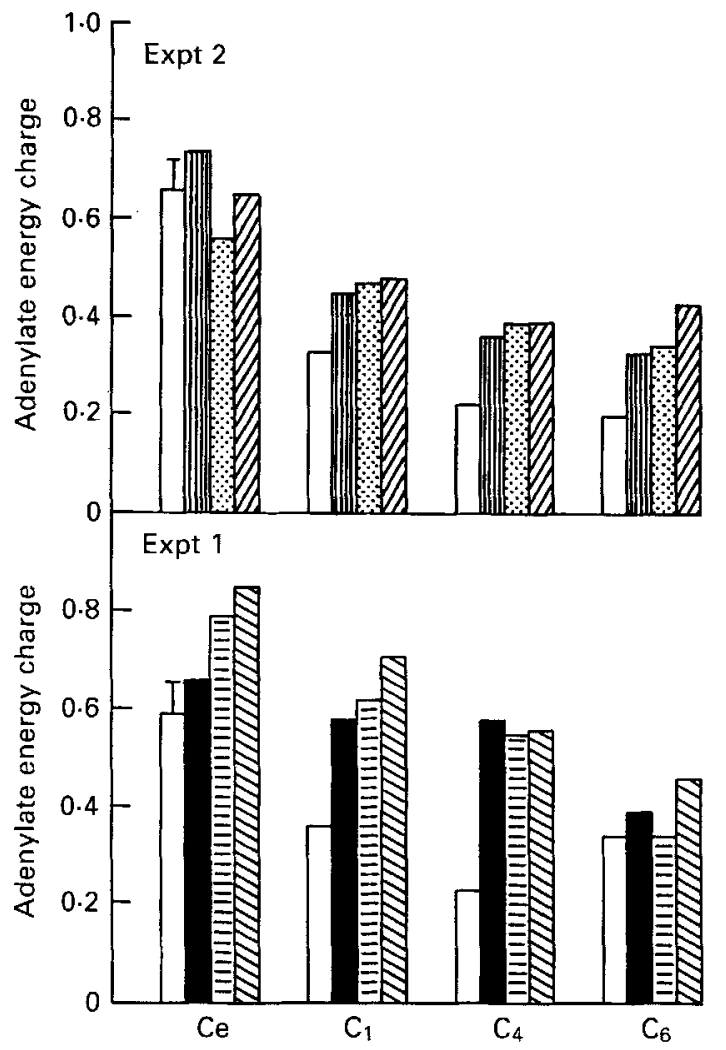

Fig. 3. Expts 1 and 2. Adenylate energy charge of the large intestinal contents of pigs. The four diets in Expt 1 were: $\square$ wheat flour, $\square$ wheat flour + aleurone, 目 wheat flour + pericarp/testa, $\$$ wheat flour + wheat bran and in Expt 2: $\square$ wheat flour, 四 wheat flour +oat bran, 圈 rolled oats and rolled oats + oat bran. The various segments of the gastrointestinal tract were: $\mathrm{Ce}$, caecum; $\mathrm{C}_{1}$, proximal colon; $\mathrm{C}_{2}$ and $\mathrm{C}_{3}$, ascending colon; $\mathrm{C}_{4}$ and $\mathrm{C}_{5}$, descending colon; and $\mathrm{C}_{6}$, distal colon. Values are means with their standard errors represented by vertical bars. For details of diets see Table 1.

values of $0 \cdot 35-0 \cdot 37$ in the proximal, $0 \cdot 20-0 \cdot 25$ in the mid- and $0 \cdot 20-0 \cdot 34$ in the distal colon. When DF was added to the diets, the decreases in AEC were less significant. For the DFenriched diets in Expt 1, AEC was 0.58-0.71 in the proximal colon, 0.55-0.58 in the midcolon and $0.34-0.46$ in the distal colon. The comparable values obtained in Expt 2 were: proximal colon $0.44-0.48$; mid-colon $0 \cdot 36-0.40$ and distal colon $0 \cdot 32-0 \cdot 38$.

\section{Organic acids}

LA was the major organic acid in the stomach and small intestine (Fig. 4). In the stomach LA levels were $10-20 \mathrm{mmol} / 1$, in the small intestine $20-35 \mathrm{mmol} / \mathrm{l}$, while the concentration was $5-20 \mathrm{mmol} / 1$ throughout the caecum and colon.

The variation in SCFA concentration at the various sampling points of the GI tract was generally inverse to that of LA; the concentration of SCFA was low in the stomach $(5-10 \mathrm{mmol} / 1)$ and the first two-thirds of the small intestine $\left(\mathrm{SI}_{1}, \mathrm{SI}_{2}\right)$, while a significant increase to $12-23 \mathrm{mmol} / 1$ was measured in the lower portion of the small intestine. In the caecum a sharp rise in SCFA concentration to $100-140 \mathrm{mmol} / 1$ was seen. The SCFA concentration in colonic segments was lower, varying from $80-130 \mathrm{mmol} / 1$ in the proximal colon to $20-65 \mathrm{mmol} / 1$ in the distal colon. A similar descending pattern of SCFA 


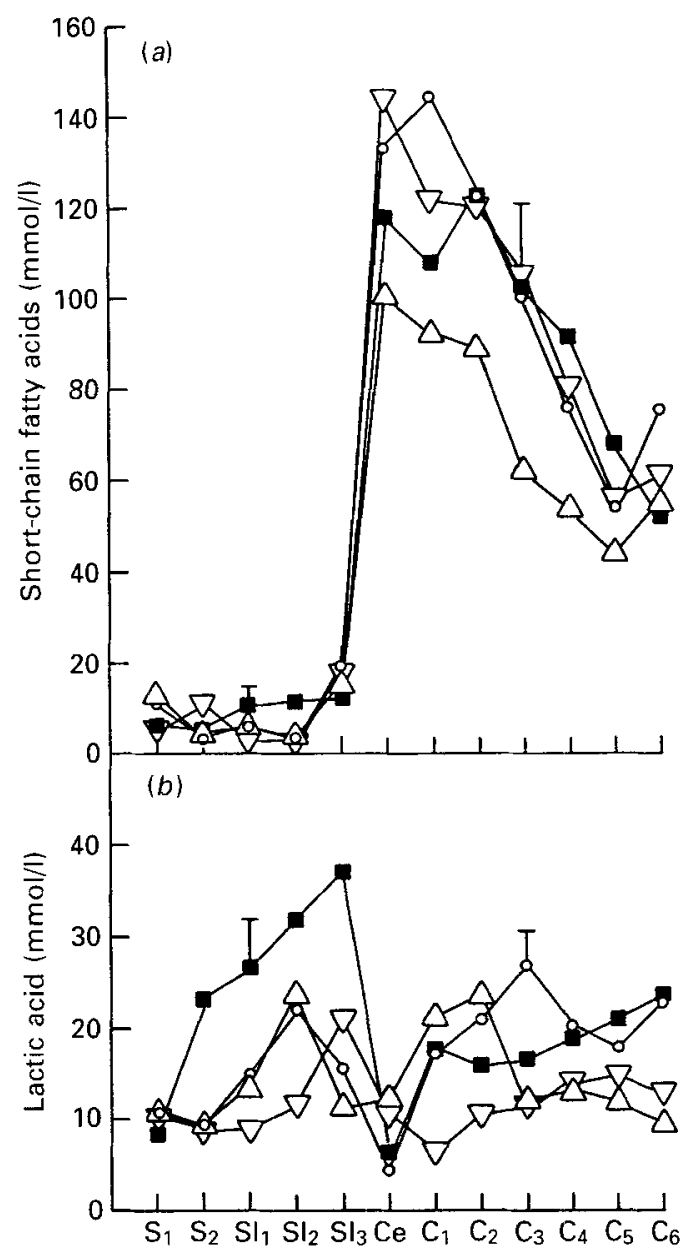

Fig. 4. Expt 2. (a) Short-chain fatty acids and (b) lactic acid (mmol/1) in the gastrointestinal content of pigs fed on the $\triangle-\triangle$ wheat flour, $-\square$ wheat flour + oat bran, $O-O$ rolled oats and $\nabla-\nabla$ rolled oats + oat bran diets. The various segments of the gastrointestinal tract were: $\mathrm{S}_{1}$ and $\mathrm{S}_{2}$, cranial and caudal halves of stomach; $\mathrm{Sl}_{1}, \mathrm{SI}_{2}$ and $\mathrm{SI}_{3}$, three equal segments of small intestine; $\mathrm{Ce}$, caecum; $\mathrm{C}_{1}$, proximal colon; $\mathrm{C}_{2}$ and $\mathrm{C}_{3}$, ascending colon; $\mathrm{C}_{4}$ and $\mathrm{C}_{5}$, descending colon; and $\mathrm{C}_{6}$, distal colon. Values are means with their standard errors represented by vertical bars. For details of diets see Table 1.

concentration throughout the colon was identified for all diets. For diet WFWB in Expt 1 and diets WFOB, RO and ROOB in Expt 2, however, there was a tendency to a higher SCFA concentration at all sampling points of the colon.

The relative contributions to SCFA of acetic and propionic acids at the various sites of the GI tract were generally inversely related (Figs. 5 and 6). Acetic acid accounted for $0.70-0.95$ of SCFA in the stomach and small intestine, $0.45-0.55$ in the caecum, $0.50-0.55$ in the proximal colon and $0 \cdot 60-0 \cdot 70$ in the distal colon. In Expt 2, however, when feeding the diets based on oats alone the increase in acetic acid in the caecum and colon was less significant, with values varying from $0.50-0.55$ in the caecum to $0.55-0.60$ in the distal colon. Propionic acid accounted for $0 \cdot 05-0.15$ in the stomach and small intestine, $0 \cdot 35-0.40$ in the caecum, $0.30-0.35$ in the proximal colon and $0.18-0.25$ in the distal colon. The contribution of butyric acid to SCFA was much lower $(0 \cdot 02-0 \cdot 12)$. In the large intestine, however, DF addition and oats in particular tended to increase the proportion of butyric 


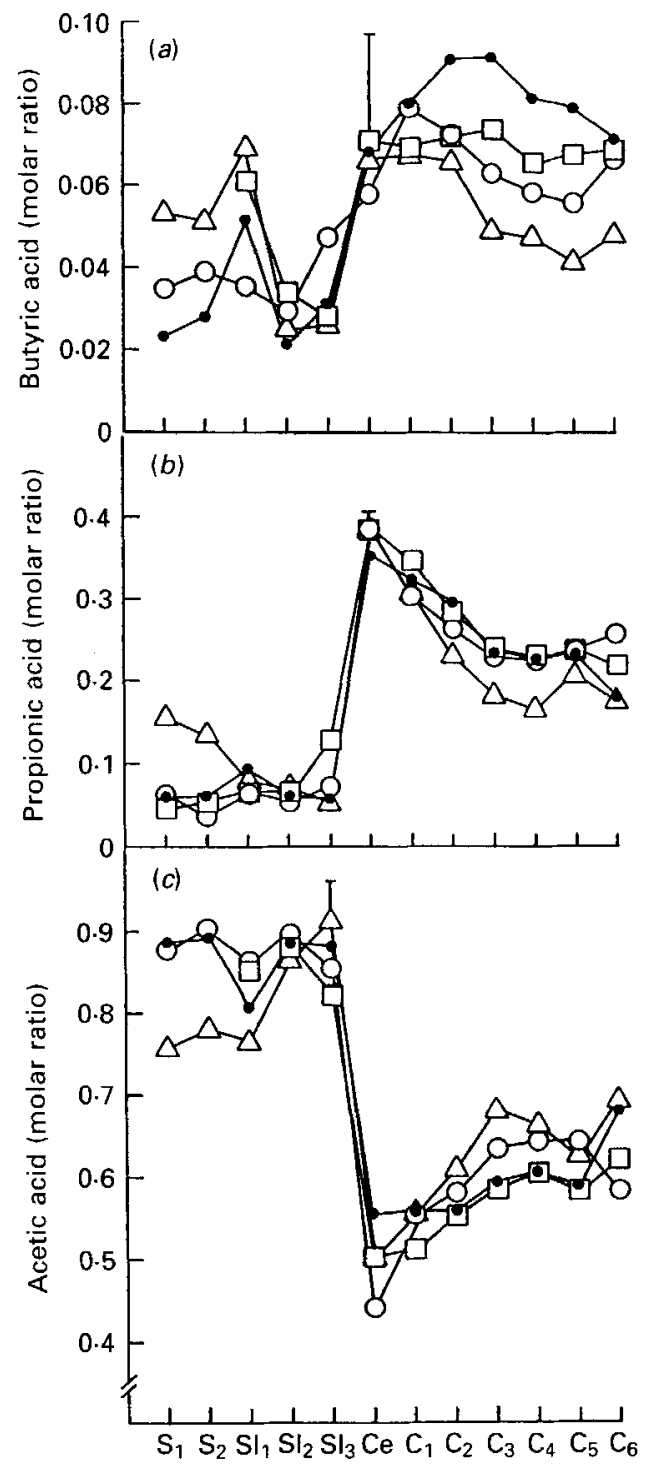

Fig. 5. Expt 1. Molar ratios of the short-chain fatty acids: (a) butyric, (b) propionic and $(c)$ acetic acids in the gastrointestinal contents of pigs fed on the following diets: wheat flour $\triangle-\triangle$, wheat flour + aleurone $O-O$, wheat flour + pericarp/testa $\square-\square$ and wheat flour + wheat bran -1 . The various segments of the gastrointestinal tract were: $\mathrm{S}_{1}$ and $\mathrm{S}_{2}$, cranial and caudal halves of stomach; $\mathrm{SI}_{1}, \mathrm{SI}_{2}$ and $\mathrm{SI}_{3}$, three equal segments of small intestine; $\mathrm{Ce}$, caecum; $\mathrm{C}_{1}$, proximal colon; $\mathrm{C}_{2}$ and $\mathrm{C}_{3}$, ascending colon; $\mathrm{C}_{4}$ and $\mathrm{C}_{5}$, descending colon ; and $\mathrm{C}_{6}$, distal colon. Values are means with their standard errors represented by vertical bars. For details of diets see Table 1 .

acid. For the branched-chain fatty acids, isobutyric acid and isovaleric acid, there was a more rapid increase in the large intestine from 0.01 and 0.015 in the caecum to 0.027 and 0.05 in the distal colon when feeding diet WF2 compared with diet ROOB (caecum 0.005 and 0.003 , distal colon 0.03 and 0.045 respectively; Fig. 7). 


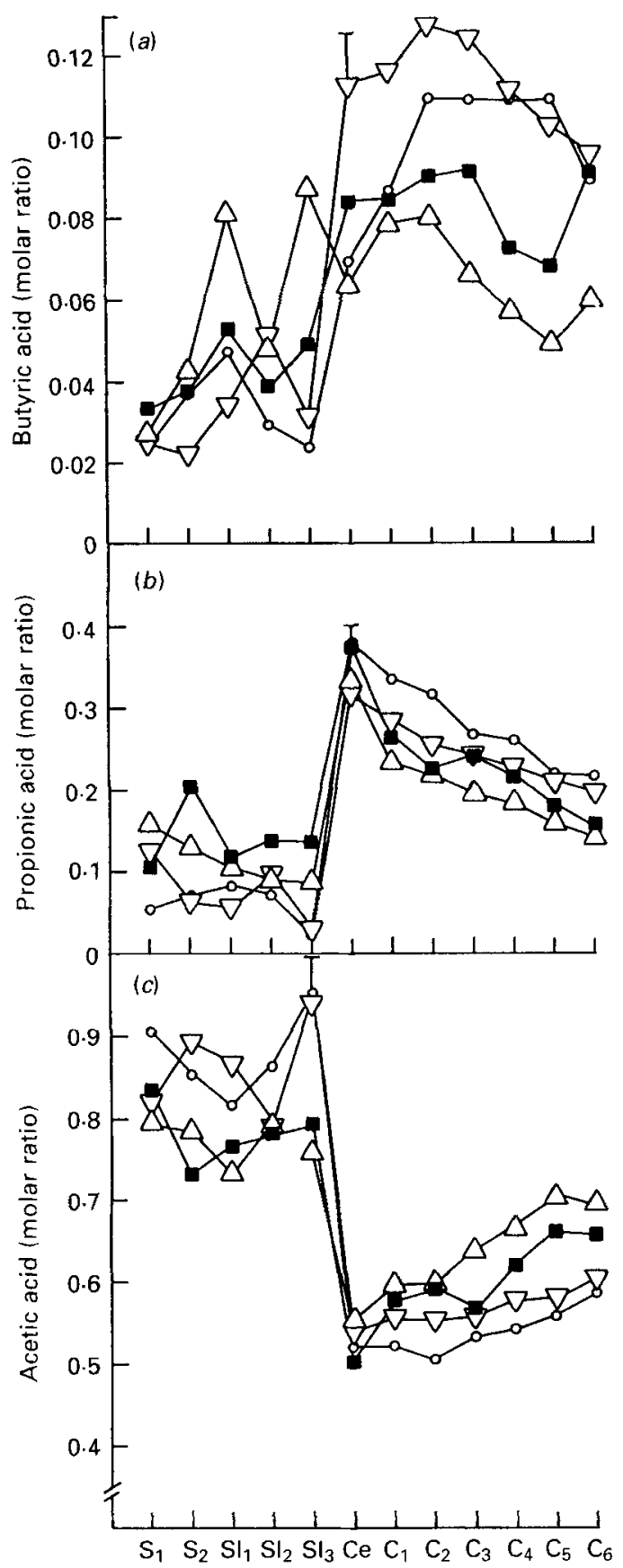

Fig. 6. Expt 2. Molar ratios of the short-chain fatty acids: $(a)$ butyric, $(b)$ propionic and $(c)$ acetic acids in the gastrointestinal contents of pigs fed on the following diets: wheat flour $\triangle-\triangle$, wheat flour + oat bran $\square-\square$, rolled oats $\mathrm{O}-\mathrm{O}$ and rolled oats + oat bran $\nabla-\nabla$. The various segments of the gastrointestinal tract were: $S_{1}$ and $S_{2}$, cranial and caudal halves of stomach; $\mathrm{SI}_{1}, \mathrm{SI}_{2}$ and $\mathrm{SI}_{3}$, three equal segments of small intestine; Ce, caecum: $C_{1}$, proximal colon; $C_{2}$ and $C_{3}$, ascending colon; $C_{4}$ and $C_{5}$, descending colon; and $C_{6}$, distal colon. Values are means with their standard errors represented by vertical bars. For details of diets see Table 1. 


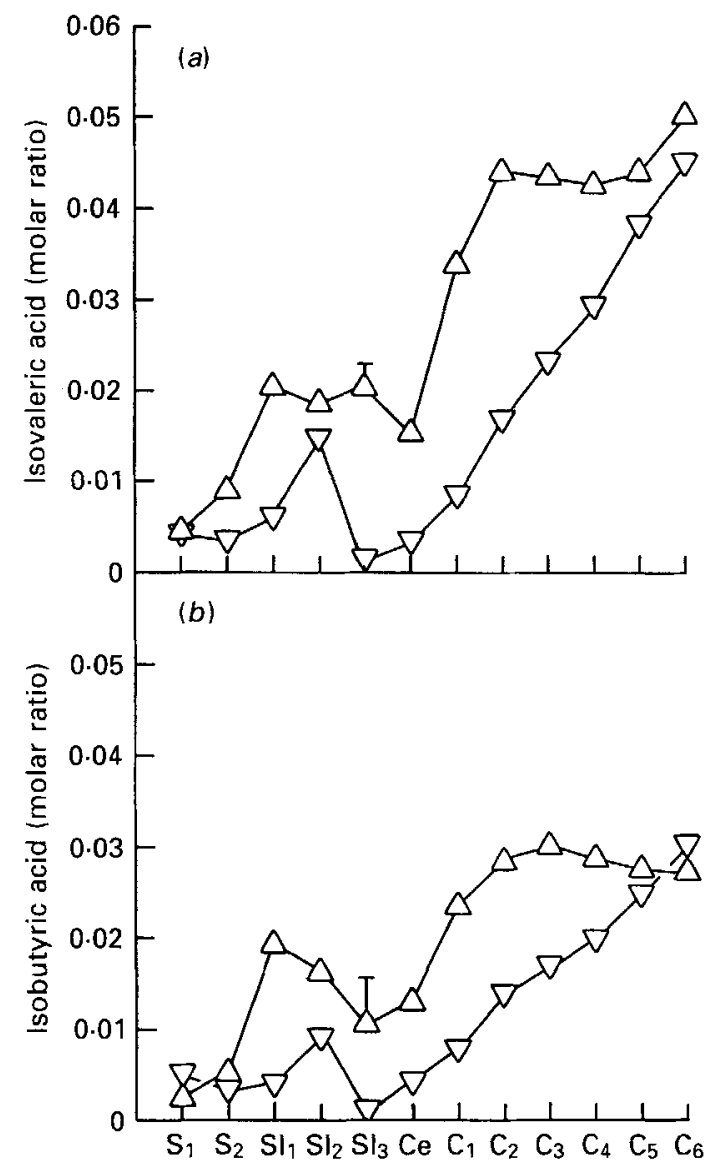

Fig. 7. Molar ratios of the short chain fatty acids: $(a)$ isovaleric and $(b)$ isobutyric acids in the gastrointestinal contents of pigs fed on the following diets: wheat flour $\triangle-\triangle$, rolled oats oat bran $\nabla-\nabla$. The various segments of the gastrointestinal tract were: $\mathrm{S}_{1}$ and $\mathrm{S}_{2}$, cranial and caudal halves of the stomach; $\mathrm{SI}_{1}, \mathrm{SI}_{2}$ and $\mathrm{SI}_{3}$, three equal segments of small intestine; $C$, caecum; $C_{1}$, proximal colon; $C_{2}$ and $C_{3}$, ascending colon; $C_{4}$ and $C_{5}$, descending colon; and $\mathrm{C}_{6}$, distal colon. Values are means with their standard errors represented by vertical bars. For details of diets see Table 1 .

\section{$p H$}

Digesta $\mathrm{pH}$ in the cranial and caudal halves of the stomach was quite similar (Fig. 8). $\mathrm{pH}$ increased along the small intestine, reaching values of 6.6-7.2 near the ileo-caecal junction. The $\mathrm{pH}$ then dropped to $5 \cdot 7-6 \cdot 8$ in the caecum. In the colon $\mathrm{pH}$ increased particularly for the DF-depleted wheat flour diet which in the mid-colon $\left(\mathrm{C}_{3}-\mathrm{C}_{5}\right)$ had a $\mathrm{pH}$ of $7 \cdot 5$. This can be compared with 6.7-6.8 $(P<0.05)$ with diets WFA and WFWB and 6.0-6.5 with diets WFOB, RO and ROOB. Diet WFPT was in between these two extremes. In the distal colon, however, pH was about $6 \cdot 5-6.8$ for all diets.

\section{DISCUSSION}

The microbial activity measured as the ATP concentration of digesta confirms that the microbial activity at the various sites of the pig GI tract varies. Under normal physiological conditions the population of micro-organisms is low in the stomach and the cranial half of the small intestine (Fuller et al. 1960), while it increases rapidly to $10^{7}-10^{9}$ culturable bacteria per gram digesta, mostly lactobacilli and streptococci, in the distal part of the 


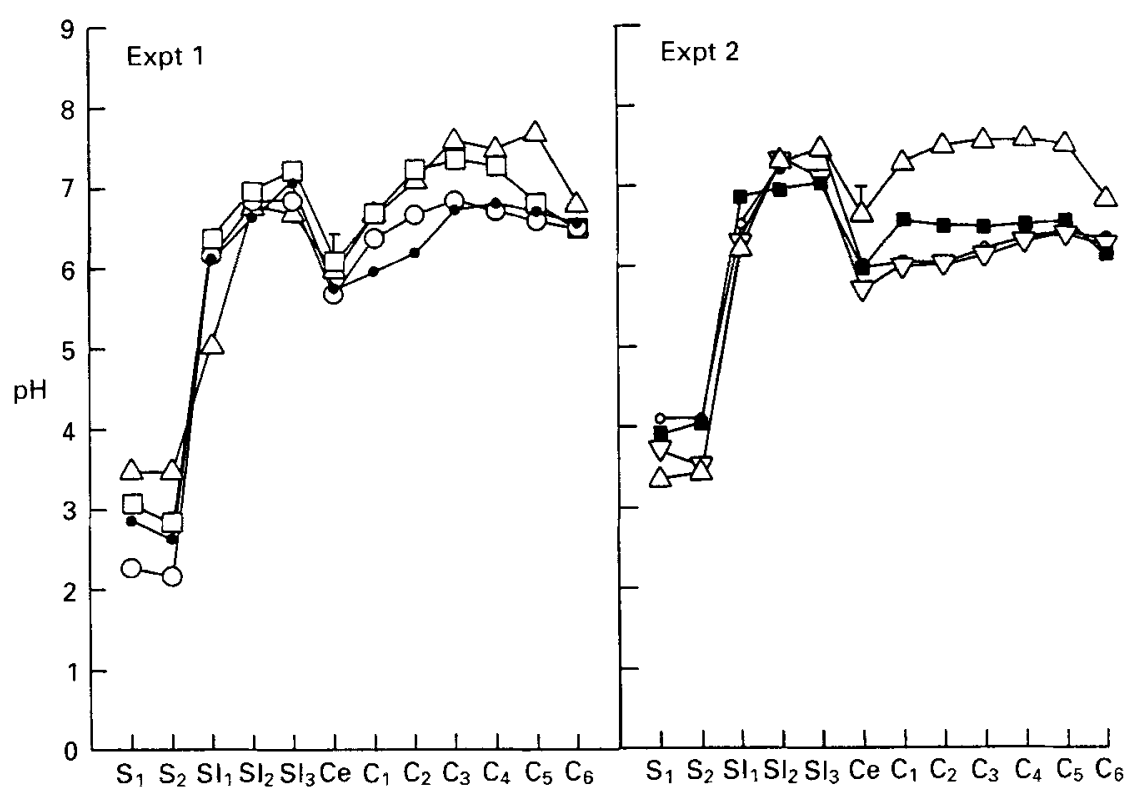

Fig. 8. Expts 1 and 2. pH in gastrointestinal contents of pigs. The four diets in Expt 1 were: $\triangle-\triangle$ wheat flour, $\mathrm{O}-\mathrm{O}$ wheat flour + aleurone, $\square-\square$ wheat flour + pericarp/testa, - wheat flour + wheat bran and in Expt 2: $\triangle-\triangle$ wheat flour, $-\square$ wheat flour + oat bran, $\bigcirc-\bigcirc$ rolled oats and $\nabla-\nabla$ rolled oats + oat bran. The various segments of the gastrointestinal tract were: $\mathrm{S}_{1}$ and $\mathrm{S}_{2}$, cranial and caudal halves of the stomach; $\mathrm{SI}_{1}, \mathrm{SI}_{2}$ and $\mathrm{SI}_{3}$, three equal segments of small intestine; $\mathrm{Ce}$, caecum; $\mathrm{C}_{1}$, proximal colon; $\mathrm{C}_{2}$ and $\mathrm{C}_{3}$, ascending colon; $\mathrm{C}_{4}$ and $\mathrm{C}_{5}$, descending colon; and $\mathrm{C}_{6}$, distal colon. Values are means with their standard errors represented by vertical bars. For details of diets see Table 1.

small intestine (Savage, 1977). The large intestine of pigs (and man) contains a vast number of different micro-organisms (400-500 species in man; Borriello, 1986) and reaches concentrations as high as $10^{11} / \mathrm{g}$ digesta (Decuypere \& Van der Heyde, 1972). Studies at this Institute with pigs confirmed these results, giving values for microbial density in the lower third of the small intestine of $10^{8}-10^{9}$, in the caecum of $10^{9}-10^{10}$, and in the mid- and distal colon of $10^{10}-10^{11}$ (Jensen, 1988).

Although the density of micro-organisms in the caecum and colon is believed to be quite constant, the decrease in ATP concentration and AEC values from the caecum and proximal colon to the distal colon suggests a decrease in metabolic activity once the energy becomes limiting during the movement through the large intestine. Studies with pure rumen bacteria (Forsberg \& Lam, 1977; Nuzback et al. 1983) and with mixed populations from pig's caecum (B. B. Jensen, unpublished ) in batch cultures have shown that the ATP pool size is higher during early exponential growth, but decreases rapidly during the stationary phase. The substrates in caecum and proximal colon with all diets are the readily fermentable carbohydrates, such as starch and sugar residues, mucus and soluble NSP which are known to favour propionic-producing micro-organisms (Leng, 1969; Wolin, 1975). The consequence is a rapid proliferation, a decrease in $\mathrm{pH}$ and an increase in propionic acid levels. As digesta moves aborally it is depleted of readily fermentable energy sources. The substrate available in the distal colon comprises, therefore, the least degradable cell wall materials of the ligno-cellulose type (Bach Knudsen \& Hansen, 1991). These conditions are known to favour acetic acid-producing micro-organisms (Leng, 1969). At the stage of energy limitation the microflora certainly become more proteolytic. However, as judged from the descending ATP concentration in the colon and the relative 
proportion of branched-chain fatty acids of SCFA, derived from fermentative breakdown of branched-chain amino acids (Macfarlane et al. 1986), the state of energy limitation occurs at various stages along the colon depending on dietary composition. With the diets providing the least fermentable substrate (the control diets) there was a much more rapid decrease in ATP concentration and a concurrent increase in branched-chain fatty acids compared with the diet providing the most fermentable substrates (diet ROOB).

The fact that energy under many conditions may be a limiting factor for microbial growth in the colon is certainly the main reason for the relatively low AEC values obtained in the colon compared with the caecum and rumen (0.68-0.92) (Erfle et al. 1979; 1981; Wallace \& West, 1982). For the control diets, AEC in the colon was $0 \cdot 2-0 \cdot 4$, far below 0.5 where viability under in vitro conditions is lost (Chapman et al. 1971). However, even when sufficient amounts of energy reached the large intestine to keep ATP concentrations high (diet ROOB), the AEC in the colon was below 0.5. For diet ROOB the relatively low AEC values may be due to its lack of bulky substances (Bach Knudsen \& Hansen, 1991) which facilitates a longer retention time in the large intestine and, thus, causes a reduction in survival of bacterial cells. One factor worth discussing here is the sampling procedure. Studies in vitro aiming at a simulation of the conditions during slaughtering; e.g. the exposure of gut contents to air, the time elapsed between slaughtering and sampling $(5-20 \mathrm{~min})$ and the temperature fall $\left(37-25^{\circ}\right)$, show no drastic effect on the fraction of the adenylate pool containing anhydride-bound phosphate of high energy for hydrolysis (B. B. Jensen, unpublished results). However, it is critical that care was taken to avoid drastic cooling of the digesta before adenylates were extracted in the perchloric acid solution. On this basis it is concluded that the low AEC values are not due to bad sampling procedures.

The results from the present study confirm that the carbohydrates, in particular NSP, are the principal energy substrates for large intestine microbial fermentation. These findings also support those from the digestibility trial of Bach Knudsen \& Hansen (1991) showing that the chemical as well as the structural composition of DF is an important factor in its GI effects along the GI tract. Compared with diet WF1, the microbial activity increased as more substrate passed to the large intestine, e.g. in the form of starch (diet WF2 $v$. WF1), as the availability of DF polysaccharides at iso-DF levels rose (diets WFOB > WFA $>$ WFWB $>$ WFPT), or at increasing levels of DF (diet RO and ROOB $v$. the other six diets).

The importance of fermentation to man and other simple-stomached animals, however, lies in the products formed and their fate in the body. In agreement with other pig studies (Argenzio \& Southworth, 1974; Clemens et al. 1975), LA is the chief organic acid in the stomach and small intestine while SCFA predominate in the caecum and colon. Comparison of the SCFA results obtained in the present study with those obtained in similar studies with pigs, however, shows some marked differences (Argenzio \& Southworth, 1975; Imoto \& Namioka, 1978). In the studies of Argenzio \& Southworth (1975), and Imoto \& Namioka (1978) there was a constant acetate:propionate ratio and total SCFA concentration as the digesta moved through the large intestine. In the present study the acetate:propionate ratio increased for all diets except diets RO and ROOB. The SCFA concentration decreased over the same distance. These differences are most likely due to the relatively low DF levels of the current diets compared with conventional pig diets (Graham et al. 1986). Apart from being scarce in fermentable substrates, the low DF level results in a prolonged retention of digesta in the large intestine and, thus, an increased total absorption of nutrients. In ponies which have a slower digesta transit time than pigs, the proportion between the acids is similar to that found in the present study (Argenzio \& Southworth, 1975; Argenzio et al. 1974).

Assuming that the equations for converting carbohydrates and proteins into SCFA given 
for man (Miller \& Wolin, 1979; Macfarlane et al. 1986) are valid for pigs, the amount of fermented carbohydrates in the large intestine, in theory, leads to a production $(\mathrm{mmol} / \mathrm{d})$ of from approximately 500 for diet WFI to 1500 for diet ROOB and the amount of fermented protein from approximately 20 for diet WFPT to 90 for diet RO. In addition there is an unknown quantity of LA produced in the stomach and small intestine. Apart from providing the host with significant amounts of energy (Bach Knudsen \& Hansen, 1991) the SCFA produced might have more specific GI and metabolic effects (Cummings \& Englyst, 1987). Butyrate, particularly, is considered to have important implications for metabolism, structure and function of epithelial cells lining the large intestine (Ryan et al. 1979; Cummings \& Branch, 1982; Sakata \& Yajima, 1984) where it is the preferred fuel over glucose (Roediger, 1980). Interestingly enough, DF addition, and oat DF in particular, not only caused an increase in butyric acid production in accordance with the overall SCFA, but the type of DF source also affected the amount of butyric acid relative to the other SCFAs. Hence, while the total production of SCFAs increased from approximately $500 \mathrm{mmol} / \mathrm{d}$ for diet WF 1 to $1500 \mathrm{mmol} / \mathrm{d}$ for diet ROOB; butyric acid production increased from $35 \mathrm{mmol} / \mathrm{d}$ to $170 \mathrm{mmol} / \mathrm{d}$ for the two diets. Certainly this is one of the most important factors to consider when discussing the mitogenic response in the large intestine of certain DF sources (Lupton et al. 1988).

An association between a high DF intake and a low faecal $\mathrm{pH}$ was noted by Walker et al. (1979). The $\mathrm{pH}$ in the caecum and colon decreased as a consequence of fermentation of carbohydrates; the effect, however, was strongly influenced by the source and amount of residues reaching the large intestine. In the diets providing most fermentable substrates (diets $\mathrm{RO}$ and $\mathrm{ROOB}$ ) the $\mathrm{pH}$ was maintained in the range of $6.0-6.5$ in all segments of the caecum and colon, while $\mathrm{pH}$ increased from approximately 6.0 in the caecum to $7 \cdot 5-8.0$ in the lower segments of the colon when feeding the DF-depleted wheat flour diet. The lumen pH may influence the growth and metabolism of colonic epithelial cells (Lupton et al. 1988) and modify the degradation of bile acids. Under acid conditions the $7 \alpha$-dehydroxylation of primary bile acids is inhibited possibly through a direct effect on the enzyme or the poor solubility of these compounds in acid conditions (Cummings \& Branch, 1982).

The present and the previous study (Bach Knudsen \& Hansen, 1991) demonstrate that the effects of various types of cereal DF on the GI tract were highly correlated with the chemical as well as the structural composition of cell wall materials. It is the belief of the authors that the effects described here in the present model experiment with pigs are valid even for man.

This work was supported by the Danish Agricultural and Veterinary Research Council, The Danish Technical Research Council, and by a grant for the senior research worker from the Royal Veterinary and Agricultural University, Copenhagen. The authors would like to thank Bodil Kristensen, Vibeke Nielsen, Inge Staffeldt and Henning Laursen for excellent technical assistance and Dr Bjørn O. Eggum for his advice during the course of the work.

\section{REFERENCES}

Argenzio, R. A. \& Southworth, M. (1974). Sites of organic acid production and absorption in the gastrointestinal tract of the pig. American Journal of Physiology 228, 454-460.

Argenzio, R. A., Southworth, M. \& Stevens, C. E. (1974). Sites of organic acid production and absorption in the equine gastrointestinal tract. American Journal of Physiology 226, 1043-1050.

Argenzio, R. A. \& Whipp, S. C. (1979). Inter-relationship of sodium, chloride, bicarbonate and acetate transport by the colon of the pig. Journal of Physiology 295, 365-381.

Atkinson, D. E. \& Walton, G. M. (1967). Adenosine triphosphate conservation in metabolic regulation. Journal of Biological Chemistry 242, 3239-3241.

Bach Knudsen, K. E. \& Hansen, I. (1991). Gastrointestinal implications in pigs of wheat and oat fractions. 1. 
Digestibility and bulking properties of polysaccharides and other major constituents. British Journal of Nutrition 65, 217-232.

Bach Knudsen, K. E., Wolstrup, J. \& Eggum, B. O. (1982a). The nutritive value of botanically defined mill fractions of barley. 2. The influence of endosperm and husk of Bomi and M-1508. Zeitschrift für Tierphysiologie, Tierernährung und Futtermittelkunde 48, 276-287.

Bach Knudsen, K. E., Wolstrup, J. \& Eggum, B. O. (1982b). The influence of dietary crude fibre and microbial activity in the digestive tract on true protein digestibility and biological value. Zeitschrift für Tierphysiologie, Tierernährung und Futtermittelkunde 49, 173-180.

Bach Knudsen, K. E., Wolstrup, J. \& Eggum, B. O. (1984). The nutritive value of botanically defined mill fractions of barley. 4. The influence of hind-gut microflora in rats on digestibility of protein and energy of pericarp, testa, germ, aleuron and endosperm rich decortication fractions of the variety Bomi. Zeitschrift für Tierphysiologie, Tierernährung und Futtermittelkunde 52, 182-193.

Borriello, S. P (1986). Microbial flora of the gastrointestinal tract. In Microbial Metabolism in the Digestive Tract, pp. 2-19 [M. J. Hill, editor]. Boca Raton: CRC.

Chapman, A. G., Fall, L. \& Atkinson, D. E. (1971). Adenylate energy charge in Escherichia coli during growth and starvation. Journal of Bacteriology 108, 1072-1086.

Chen, W. J. L., Anderson, J. W. \& Jennings, D. (1984). Propionate may mediate the hypocholesterolemic effects of certain soluble plant fibers in cholesterol-fed rats. Proceedings of the Society for Experimental Biology and Medicine 175, 215-218.

Clemens, E. T., Stevens, C. E. \& Southworth, M. (1975). Sites of organic acid production and pattern of digesta movement in the gastrointestinal tract of swine. Journal of Nutrition 105, 759-768.

Cummings, J. H. (1982). Consequences of the metabolism of fibre in the human large intestine. In Dietary Fiber in Health and Disease, pp. 9-22 [G. Vahouny and D. Kritchevsky, editors]. New York: Plenum Press.

Cummings, J. H. \& Branch, W. J. (1982). Postulated mechanisms whereby fiber may protect against large bowel cancer. In Dietary Fiber in Health and Disease, pp. 313-325 [G. V. Vahouny and D. Kritchevsky, editors]. New York: Plenum Press.

Cummings, J. H. \& Englyst, H. N. (1987). Fermentation in the human large intestine and the available substrates. American Journal of Clinical Nutrition 45, 1243-1255.

Cummings, J. H., Hill, M. J., Bone, E. S., Branch, W. J. \& Jenkins, D. J. A. (1979). The effect of meat protein and dietary fibre on colonic function and metabolism. II. Bacterial metabolites in feces and urine. American Journal of Clinical Nutrition 32, 20942101.

Cummings, J. H., Pomare, E. W., Branch, W. J., Naylor, C. P.\& Macfarlane, G. T. (1987). Short chain fatty acids in human large intestine, portal, hepatic and venous blood. Gut 28, 1221-1227.

Decuypere, J. \& Van der Heyde, H. (1972). Study of the gastro-intestinal microflora of suckling piglets and early weaned piglets reared using different feeding systems. Zentralblatt für Bakteriologie, Parasitenkunde, Infektionskrankheiten und Hygiene. Erste Abieilung Originale A221, 492-510.

Erfle, J. D., Mahadevan, S. \& Sauer, F. D. (1979). Effect of diet quality on adenosine 5'-triphosphate concentration and adenylate energy charge of rumen microbes from fistulated cows. Journal of Dairy Science 62, 284-291.

Erfle, J. D., Mahadevan, S. \& Sauer, F. D. (1981). Relationship between adenylate energy charge, rumen volatile fatty acid concentrations, and rates of production and dry matter digestibility in the cow. Journal of Dairy Science 64, 634-642.

Forsberg, C. W. \& Lam, K. (1977). Use of adenosine 5 -triphosphate as an indicator of the microbiota biomass in rumen contents. Applied and Environmental Microbiology 33, 528-537.

Fuller, R., Newland, L. G. M., Briggs, C. A. E., Braude, R. \& Mitchell, K. G. (1960). The normal intestinal flora of the pig. IV. The effect of dietary supplements of penicillin, chlortetracycline or copper sulphate on the faecal flora. Journal of Applied Bacteriology 23, 195205.

Graham, H., Hesselman, K. \& Aman, P. (1986). The influence of wheat bran and sugar-beet pulp on the digestibility of dietary components in a cereal-based pig diet. Journal of Nutrition 116, 242-251.

Hill, H. (1969). The flow of food through the monogastric animal including the mechanism of the whole gut. In Handbuch der Tierernährung, vol. 1, pp. 207-254 [W. Lenkeit, K. Brierem and E. Craseman, editors]. Hamburg: Paul Parey.

Imoto, S. \& Namioka, S. (1978). VFA production in the pig large intestine. Journal of Animal Science 47, 383-395.

Jensen, B. B. (1988). Effect of diet composition and virginiamycin on microbial activity in the digestive tract of pigs. In Digestive Physiology in the Pig, pp. 392-400 [L. Buraczewska, S. Buraczewski, B. Pastusrewska and T. Zebrowska, editors]. Jablonna: Polish Academy of Sciences.

Keys, J. E. \& DeBarthe, J. V. (1974). Site and extent of carbohydrate, dry matter, energy and protein digestion and the rate of passage of grain diets in Swine. Journal of Animal Science 39, 57-62.

Leng, R. A. (1969). Formation and production of volatile fatty acids in the rumen. In Physiology of Digestion and Metabolism in the Ruminant, pp. 406-421 [A. T. Phillipson, editor]. Cambridge: Oriel Press.

Lupton, J. R., Coder, D. M. \& Jacobs, L. R. (1988). Long-term effects of fermentable fibers on rat colonic $\mathrm{pH}$ and epithelial cell cycle. Journal of Nutrition 118, 840-845.

McElroy, W. D. (1947). The energy source for bioluminescence in an isolated system. Proceedings of the National Academy of Sciences, USA 33, 342-345. 
Macfarlane, G. T., Cummings, J. H. \& Allison, C. (1986). Protein degradation by human intestinal bacteria. Journal of General Microbiology 132, 1647-1656.

McNeil, N. I., Cummings, J. H. \& James, W. P. T. (1978). Short chain fatty acid absorption by the human large intestine. Gut 19,819-822.

Mason, V. C. \& Just, A. (1976). Bacterial activity in the hind-gut of pigs. 1. Its influence on the apparent digestibility of dietary energy and fat. Zeitschrift für Tierphysiologie, Tierernährung und Futtermittelkunde $\mathbf{3 6}$ 301-310.

Miller, T. L. \& Wolin, M. J. (1979). Fermentation by saccharolytic intestinal bacteria. American Journal of Clinical Nutrition 32, 164-172.

Nuzback, D. E., Bartley, E. E., Dennis, S. M., Nagaraja, T. G., Galitzer, S. J. \& Dayton, A. D. (1983). Relation of rumen ATP concentration to bacterial and protozoal numbers. Applied and Environmental Microbiology 46 , 533-538.

Roediger, W. E. W. (1980). Role of anaerobic bacteria in the metabolic welfare of the colonic mucosa in man. Gut 21, 793--798.

Ryan, G. P., Dudrick, S. J., Copeland, E. M. \& Johnson, L. R. (1979). Effect of various diets on colonic growth in rats. Gastroenterology 77, 658-663.

Sakata, T. \& Yajima, T. (1984). Influence of short chain fatty acids on the epithelial cell division of digestive tract. Quarterly Journal of Experimental Physiology 69, 639-648.

Savage, D. C. (1977). Microbial ecology of the gastrointestinal tract. Annual Review of Microbiology 31, $107-133$

Snedecor, G. W. \& Cochran, W. G. (1973). Statistical Methods. Ames: Iowa State University Press.

Swedes, J. S., Sedo, R. J. \& Atkinson, D. E. (1975). Relation of growth and protein synthesis to the adenylate energy charge in an adenine-requiring mutant of Escherichia coli. Journal of Biological Chemistry 250 , 6930-6938.

Thore, A. (1979). Technical aspects of the bioluminescent firefly luciferase assay of ATP. Science Tools 26,3034

Walker, A. R. P., Walker, B, F.\& Segal, I. (1979). Faecal pH value and its modification by dietary means in South African black and white schoolchildren. South African Medical Journal 24, 495-498.

Wallace, R. J. \& West, A. A. (1982). Adenosine 5'triphosphate and adenylate energy charge in sheep digesta. Journal of Agricultural Science, Cambridge 98, 523-528.

Wolin, M. J. (1975). Interactions between the bacterial species of the rumen. In Digestion and Metabotism in the Ruminant, pp. 134-148 [E. W. Mc.Donald and A. Z. I. Warner, editors]. Armidale: University of New England Publishing Units.

Wolstrup, J. \& Jensen, K. (1976). Adenosine triphosphate in the bovine rumen during maximum nutrient supply and starvation. Journal of Bacteriology 41, 243-250. 